\title{
Using animal behavior in conservation management: a series of systematic reviews and maps
}

\author{
Alison L. Greggor ${ }^{1 *}$, Daniel T. Blumstein ${ }^{2}$, Bob B. M. Wong ${ }^{3}$ and Oded Berger-Tal ${ }^{4}$
}

In the past few decades there has been a growing understanding of the role animal behavior research can play in improving the effectiveness and success of conservation management programs. Animal behavior can help us understand and predict the impacts of anthropogenic disturbance on wildlife populations, can be used as a tool in conservation interventions, and can serve as a powerful indicator of conservation problems [1]. Overall, the emergent field of conservation behavior (applying animal behavior research to conservation and management) has already contributed to many successful conservation outcomes-from devising individual-specific diets to manage sex ratios in the critically endangered Kakapo [2], to promoting life skills that enhance survival after reintroduction of species into the wild [3-6]. Nevertheless, there is tremendous room for improvement. For example, olfactory deterrents can fail because they do not adequately recognize or manipulate context in the meaning of animal signals [7]. Meanwhile, traps designed in the laboratory to attract and control invasive species can prove ineffective under field conditions [8]. In many such cases, we simply do not understand the underlying causes of failures, which prevent us from offering sound and cost-effective guidance on conservation management. These failures and a common disregard for behavior in conservation settings have led to the valid criticism that the field lacks impact. We argue that the relevance of the field hinges on us being able to openly admit, distinguish, and understand where and why applying a behavioral

\footnotetext{
*Correspondence: AGreggor@sandiegozoo.org

${ }^{1}$ Institute for Conservation Research, San Diego Zoo Global, Escondido, CA 92027, USA

Full list of author information is available at the end of the article
}

approach succeeds and fails in improving conservation or management outcomes.

This special issue represents a collective push towards creating a sound and reliable evidence base for conservation behavior mechanisms and interventions. Conceived during a systematic review training workshop [9], we hope that this collection of protocols and evidence syntheses will illustrate the power of the systematic review model for reducing bias, and rigorously evaluating evidence for and against the uses of conservation behavior. We also hope that the special issue will highlight some areas where animal behavior research can be effectively used to improve conservation success. In doing so, we offer a commitment to practitioners that we as scientists are striving for more transparent methods, communication and awareness of where our recommendations are actually useful. Additionally, by choosing the Environmental Evidence format which requires publishing protocols ahead of conducting reviews, we reduce the likelihood that other scientists will embark on these topics unaware of potentially duplicated efforts, as well as increase the credibility of the reviews.

This special issue covers topics that span a variety of conservation behavior applications, aimed at better understanding mechanisms to designing interventions; all of which have been flagged as research priorities for conservation behavior [10]. From exploring interventions that attract animals via scent lures [11] or acoustic playbacks [12], to mapping interventions that tap into learning to deter animals from human-conflict scenarios [13]; the potential applications highlighted in this issue are diverse. That being said, the applications and priorities of conservation behavior are much broader than the topics we cover. Therefore we see this as merely the beginning 
of a practice that we hope to become commonplace for animal behavior scientists interested in having greater conservation relevance for their work.

The special issue contains protocols for both systematic reviews and maps. Some interventions are currently very targeted (e.g. anti-predator training for translocated animals [14]), while others still need to document the broader effects of basic phenomenon (e.g. the impact of light pollution on behavior $[15,16]$, or the ways animals change their acoustic communication in response to noise pollution [17]). The diversity in the breadth of topics reflects the uneven state of knowledge in the conservation behavior field. Some applications are accepted and well-known, yet we still lack a deeper understanding of their effectiveness. Meanwhile, others are much more diffuse, and cover broader topics that deserve mapping before specific recommendations can be made.

As part of this multi-scale collaborative effort, each systematic map or review protocol in this issue is collecting a set of similar meta-data variables in addition to the variables that directly relate to their research question. The broader analysis from the shared variables will help us better understand the prevalence and biases in existing conservation behavior interventions. There may be geographical, species-level and intervention-type biases that need to be addressed in arenas of scientific planning. Therefore, when the group of reviews and maps are ultimately published, we will have a basis for evaluating evidence in specific areas of conservation behavior, and a snapshot of the biases present within diverse areas of the field.

Conservation behavior will not solve all or even most conservation problems. However, if we can increase the effectiveness of even a portion of the potential applications of behavior, the expansion of these targeted methods could create dramatic improvements for certain species, habitats or ecosystems. The recent publishing of protocols outside of this issue that cover aspects of conservation behavior (e.g. [18]), suggest the momentum and appetite for this type of evidence is growing. Comparative effectiveness evaluation must follow all of these initial analyses; once identified, the estimated costs and logistical challenges of effective strategies and interventions must be compared with other existing methods [19]. In this way, conservation behavior can be more than a promise, but a tangible, reliable, cost-effective method for predicting and advancing conservation outcomes.

\section{Acknowledgements}

This special issue the product of an international training workshop by the Collaboration for Environmental Evidence specifically tailored for behavioral ecologists and held at the Jacob Blaustein Institutes for Desert Research, BenGurion University of the Negev, Israel. We thank MISTRA-EviEM and Stockholm Environment Institute, Sweden for allocating time to Biljana Macura for running the training workshop. The workshop was made possible through a collaborative research grant jointly funded by Ben-Gurion University and Monash University, Australia, as well as generous additional support from the Jacob Blaustein Center for Scientific Cooperation, The Swiss Institute for Dryland Environmental and Energy Research, the Mitrani Department of Desert Ecology, and the Ben- Gurion University of the Negev. This is publication number 1017 of the Mitrani Department of Desert Ecology.

\section{About this supplement}

This article has been published as part of Environmental Evidence Volume 8 Supplement 1, 2019: Using animal behavior in conservation management. The full contents of the supplement are available online at https://environmen talevidencejournal.biomedcentral.com/articles/supplements/volume-8-suppl ement-1.

\section{Authors' contributions}

All authors contributed to the conception and editing of the manuscript. All authors read and approved the final manuscript.

\section{Funding}

Publication of this supplement has not been supported by sponsorship.

Availability of data and materials

Not applicable.

Ethics approval and consent to participate

Not applicable.

Consent for publications

Not applicable.

Competing interests

The authors declare that they have no competing interests.

\section{Author details}

${ }^{1}$ Institute for Conservation Research, San Diego Zoo Global, Escondido, CA 92027, USA. ${ }^{2}$ Department of Ecology and Evolutionary Biology, University of California, Los Angeles, CA 92697, USA. ${ }^{3}$ School of Biological Sciences, Monash University, Victoria 3800, Australia. ${ }^{4}$ Mitrani Department of Desert Ecology, Ben-Gurion University of the Negev, 8499000 Midreshet Ben Gurion, Israel.

Published: 13 June 2019

\section{References}

1. Berger-Tal O, PolakT, Oron A, Lubin Y, Kotler BP, Saltz D. Integrating animal behavior and conservation biology: a conceptual framework. Behav Ecol. 2011;22:236-9.

2. Robertson BC, Elliott GP, Eason DK, Clout MN, Gemmell NJ. Sex allocation theory aids species conservation. Biol Lett. 2006;2:229-31. https://doi. org/10.1098/rsbl.2005.0430.

3. Shier DM, Owings D. Effects of predator training on behavior and postrelease survival of captive prairie dogs. Biol Conserv. 2006;132:126-35.

4. Vargas A, Anderson SH. Effects of experience and cage enrichment on predatory skills of black-footed ferrets (Mustela nigripes). J Mammal. 1999;80:263-9.

5. Beck B, Casgro M, Stoinski T, Ballou J. The effects of prerelease environments and postrelease management on survivorship in reintroduced golden lion tamarins. In: Kleiman D, Rylands A, editors. Lion tamarins Biol Conserv. Washington, DC: Smithsonian Institution Press; 2002. p. 283-300.

6. Whiteside MA, Sage R, Madden JR. Diet complexity in early life affects survival in released pheasants by altering foraging efficiency, food choice, handling skills and gut morphology. J Anim Ecol. 2015;84:1480-9.

7. Parsons MH, Apfelbach R, Banks PB, Cameron EZ, Dickman CR, Frank ASK, et al. Biologically meaningful scents: a framework for understanding predator-prey research across disciplines. Biol Rev. 2018;93:98-114.

8. Hurley BP, Garnas J, Cooperband MF. Assessing trap and lure effectiveness for the monitoring of Sirex noctilio. Agric For Entomol. 2015;17:64-70. 
9. Berger-Tal O, Greggor AL, Macura B, Adams CA, Blumenthal A, Bouskila $A$, et al. Systematic reviews and maps as tools for applying behavioral ecology to management and policy. Behav Ecol. 2018. https://doi. org/10.1093/beheco/ary130/5123582.

10. Greggor AL, Berger-Tal O, Blumstein DT, Angeloni L, Bessa-Gomes C, Blackwell BF, et al. Research priorities from animal behaviour for maximising conservation progress. Trends Ecol Evol. 2016;31:953-64.

11. Price JC, Banks PB, Greggor AL. What evidence exists on the effectiveness of different types of olfactory lures as attractants for invasive mammalian predators? A systematic map protocol. Environ Evid. 2019. https://doi. org/10.1186/s13750-019-0156-4.

12. Putman BJ, Blumstein DT. What is the effectiveness of using conspecific or heterospecific acoustic playbacks for the attraction of animals for wildlife management? A systematic review protocol. Environ Evid. 2019 https://doi.org/10.1186/s13750-019-0149-3.

13. Snijders L, Greggor AL, Hilderink F, Doran C. Effectiveness of animal conditioning interventions in reducing Human-wildlife conflict. A systematic map protocol. Environ Evid. 2019. https://doi.org/10.1186/s1375 0-019-0153-7.

14. Greggor AL, Price C, Shier DM. Examining the efficacy of anti-predator training for increasing survival in conservation translocations. Environ Evid. 2019. https://doi.org/10.1186/s13750-019-0154-6.

15. McLay L, Hopkins J, Wong BB, Candolin U, Jones T. What is the available evidence that artificial light at night affects animal behavior? A systematic map protocol. Enrivon Evid. 2019. https://doi.org/10.1186/ s13750-019-0151-9.

16. Adams CA, Blumenthal A, Fernández-Juricic E, Bayne E, St. Clair CC. Effect of anthropogenic light on bird movement, habitat selection and distribution: a systematic map protocol. Environ Evid. 2019. https://doi. org/10.1186/s13750-019-0155-5.

17. Berger-Tal O, Wong BBM, Candolin U, Barber J. What evidence exists on the effects of anthropogenic noise on acoustic communication in animals? A systematic map protocol. Environ Evid. 2019. https://doi. org/10.1186/s13750-019-0165-3.

18. Sordello R, De Lachapelle FF, Livoreil B, Vanpeene S. Evidence of the environmental impact of noise pollution on biodiversity: a systematic map protocol. Environ Evid. 2019;8:8.

19. Blumstein DT, Berger-Tal O. Understanding sensory mechanisms to develop effective conservation and management tools. Curr Opin Behav Sci. 2015;6:13-8.

\section{Publisher's Note}

Springer Nature remains neutral with regard to jurisdictional claims in published maps and institutional affiliations.
Ready to submit your research? Choose BMC and benefit from:

- fast, convenient online submission

- thorough peer review by experienced researchers in your field

- rapid publication on acceptance

- support for research data, including large and complex data types

- gold Open Access which fosters wider collaboration and increased citations

- maximum visibility for your research: over $100 \mathrm{M}$ website views per year

At BMC, research is always in progress.

Learn more biomedcentral.com/submissions 